\title{
Long-term follow-up of pediatric head trauma patients treated at Mulago National Referral Hospital in Uganda
}

\author{
Silvia D. Vaca, BS, ${ }^{1,2}$ Linda W. Xu, MD, ${ }^{1,2}$ Juliet Nalwanga, MBChB, MMed Surg, ${ }^{3}$ \\ Christine Muhumuza, MPH, ${ }^{4}$ Benjamin J. Lerman, BS, ${ }^{1,2}$ Joel Kiryabwire, MBChB, MMed Surg, ${ }^{3}$ \\ Hussein Ssenyonjo, MBChB, MMed Surg, ${ }^{3}$ John Mukasa, MBChB, MMed Surg, ${ }^{3}$ \\ Michael Muhumuza, MBChB, MMed Surg, ${ }^{3}$ Michael Haglund, MD, PhD,, 5 and Gerald Grant, MD ${ }^{1,2}$ \\ 1Department of Neurosurgery, Stanford University; ${ }^{2}$ Stanford Center for Global Health Innovation, Palo Alto, California; \\ ${ }^{3}$ Department of Neurosurgery, Mulago National Referral Hospital; ${ }^{4}$ School of Public Health, Makerere University, Kampala, \\ Uganda; ${ }^{5}$ Department of Neurosurgery, Duke University; and ${ }^{6}$ Duke University Division of Global Neurosurgery and \\ Neuroscience, Durham, North Carolina
}

OBJECTIVE There is a paucity of literature on long-term neurosurgical outcomes in sub-Saharan Africa, and as neurosurgical services expand in each country, it would be beneficial to understand the impact of these services on the national population. Since follow-up can be inconsistent, the authors here used the novel method of telephone surveys to conduct the first-ever long-term follow-up in Uganda to elucidate the outcomes of pediatric head trauma patients treated at the national referral hospital.

METHODS A prospectively maintained database of pediatric head trauma patients treated at the Mulago National Referral Hospital (MNRH) between 2014 and 2015 included 232 patients eligible for this study. Quality of life was assessed through phone surveys conducted by a Ugandan collaborator on site who performed all interviews with the guardian listed at the time of hospital admission, using each participant's language.

RESULTS Phone interviews were completed for 142 patients, resulting in a 61\% response rate. Including inpatient deaths, the mortality rate was $10 \%$. Almost half of the patients (48\%) did not return to MNRH postdischarge, and $37 \%$ received no subsequent healthcare at all. Including inpatient deaths, the average Extended Glasgow Outcome ScalePediatric Revision (GOSE-Peds) scores for patients with severe, moderate, and mild head trauma were $5.68 \pm 2.85,4.79$ \pm 2.38 , and $3.12 \pm 2.08$, respectively, at 1 year postinjury and $5.56 \pm 2.58,4.00 \pm 2.45$, and $2.21 \pm 1.49$, respectively, at 2 years postinjury.

CONCLUSIONS This first-ever long-term follow-up of pediatric head trauma patients in Uganda confirmed the feasibility of a novel phone follow-up method for patients throughout Uganda. The results at 2 years showed poor long-term recovery in patients who suffered moderate or severe head trauma but good recovery in patients who suffered mild head trauma. However, there was greater overall disability than that in comparable head trauma studies in the US. The current study lays the groundwork for phone follow-up in low- and middle-income countries as a viable way to obtain outcome data.

https://thejns.org/doi/abs/10.3171/2018.7.PEDS17601

KEYWORDS follow-up; global neurosurgery; head trauma; outcome; pediatric TBI; Uganda

$\mathrm{T}$ RAUMATIC brain injury (TBI) is a broad category encompassing any brain function disruption secondary to mechanical forces applied to the skull. ${ }^{15}$ As a leading cause of pediatric death, TBI is a global public health issue. ${ }^{4,5,7,12}$ In a qualitative review of 30 studies from
18 different countries, Dewan et al. determined that the incidence of pediatric TBI ranges from 12 cases per 100,000 persons in Sweden to 486 cases per 100,000 persons in Australia, with more than $80 \%$ of cases considered to be mild-defined as a Glasgow Coma Scale (GCS) score of

ABBREVIATIONS GCS = Glasgow Coma Scale; GOS = Glasgow Outcome Scale; GOS-E = Extended GOS; GOSE-Peds = Extended GOS-Pediatric Revision; MNRH = Mulago National Referral Hospital; RTI = road traffic injury; TBI = traumatic brain injury.

SUBMITTED November 2, 2017. ACCEPTED July 24, 2018.

INCLUDE WHEN CITING Published online October 19, 2018; DOI: 10.3171/2018.7.PEDS17601. 
13 or greater-and less than $10 \%$ requiring surgical intervention. ${ }^{7,8,19}$ In the US, pediatric TBI is responsible for 435,000 emergency department visits; 37,000 hospitalizations; and 2685 deaths per year. ${ }^{26}$ Few studies have characterized the epidemiology of pediatric TBI in African countries. Single-center studies in Nigeria and South Africa have found a peak incidence around 6 years of age, with motor vehicle crashes as the leading cause of pediatric head injuries, followed by falls and violence. ${ }^{23,28} \mathrm{In}$ contrast, falling is the leading cause of pediatric TBI hospitalizations in the US, followed by motor vehicle crashes and blunt trauma. ${ }^{4}$

Pediatric TBI can have a variety of long-term consequences, ranging from physical to neurobehavioral, cognitive, and social impairments. ${ }^{5,12,22}$ The Centers for Disease Control and Prevention estimates that 145,000 children in the US are living with long-term social, behavioral, physical, or cognitive functioning impairments due to TBI. ${ }^{4}$ The effects of pediatric TBI can present over time, requiring rehabilitation along with school and family support. Long-term outcomes of children with TBI can be tracked through a variety of scales and assessments. The most widely used measure of global outcome following TBI is the Glasgow Outcome Scale (GOS). ${ }^{11}$ Extended versions of the GOS-named the Extended GOS (GOS-E) and the Extended GOS-Pediatric Revision (GOSE-Peds)have been validated for both adult and pediatric populations to address the limitations of the original GOS., ${ }^{3,27}$ The GOSE-Peds is considered the core measurement for global outcome in pediatric TBI. ${ }^{18}$ Both the GOSE-Peds and the GOS-E are eight-point scales ranging from death to upper good recovery, which correlates to the five-point GOS ranging from death to low disability.

In a US study evaluating pediatric patients with severe TBI (GCS score 3 and 4), Fulkerson et al. calculated a $56.7 \%$ mortality rate at the 1-year follow-up, with an average GOS score of moderate disability in survivors. ${ }^{9}$ A separate 30-month follow-up study in the US showed lower moderate disability in severe TBI patients and good recovery for those with moderate and mild TBI. ${ }^{1}$ There is a paucity of literature on long-term pediatric TBI outcomes in sub-Saharan Africa, and as neurosurgical services expand in each country, the impact of these services on the national population remains largely unknown. The prevalence of differing mechanisms of injury coupled with limited in-hospital and post-hospital resources for recovering TBI patients makes it difficult to estimate outcomes based on available data from high-income countries and lowand middle-income countries. Thus, assessment of longterm pediatric TBI outcomes is warranted in each of these countries.

Mulago National Referral Hospital (MNRH) in Kampala, Uganda, employs four of the eight available neurosurgeons in the country, which has a population of 41 million people (https://data.worldbank.org/country/uganda). ${ }^{10}$ Because MNRH is the single national referral hospital in the country, its patients come from all regions of Uganda. Long-term follow-up in this setting is especially challenging due to inconsistent clinical follow-up, with no regular access to patients after discharge. To overcome these challenges, authors of neurosurgical follow-up studies in a regional hospital in eastern Uganda relied on costly, time-intensive home visits limited to nearby districts. ${ }^{24,30,31}$ Additional challenges at MNRH are the lack of a centralized patient census and patient records kept on paper charts.

Phone surveys have long been utilized in high-income countries for health research., ${ }^{2,616,20}$ The rapid worldwide increase in mobile phone ownership in the last decade has suggested the feasibility of phone surveys, as demonstrated in recent studies in low- and middle-income countries such as China and Cote d'Ivoire. ${ }^{14,33}$ A 2017 study in Indonesia reported phone follow-up as a viable option for their neurosurgical population. ${ }^{17,26}$ In Uganda, adult mobile phone ownership has increased from $10 \%$ in 2002 to $65 \%$ in 2014 (compared to 85\% in the US in 2014). ${ }^{21}$ In the current study, we used a prospectively maintained patient database and phone surveys to conduct the first-ever long-term follow-up of pediatric head trauma patients in Uganda.

\section{Methods \\ Ethics Approval}

Ethics approval was provided by the Stanford University Institutional Review Board (IRB) in the US and the Makerere University IRB in Uganda.

\section{Patient Database}

Phone numbers, cause of injury, CT findings, surgical intervention, and admission and discharge GCS scores of pediatric head trauma patients treated at MNRH between 2014 and 2015 had been obtained prospectively. Any person 17 years old or younger who had been admitted to the neurosurgical service at MNRH and discharged between 2014 and 2015 was eligible for inclusion in the study. Of 347 patients seen in that time period, 30 had died during their hospital stay, and 85 did not have a phone number on file. Thus, 232 patients were eligible for our study. Of these, 142 patients were reached via phone and completed interviews in 2016. These patients were divided into 1-year $(n=72)$ and 2-year $(n=70)$ follow-up groups based on the time to the follow-up call regardless of when mortalities occurred.

\section{Survey Development}

Phone surveys were designed to assess the patient's health following discharge from the neurosurgical department at MNRH. Questions covered patient demographics, mortality, follow-up healthcare, neurological outcomes, and quality of life measures. Neurological outcomes were assessed using the GOSE-Peds. ${ }^{3}$ Quality of life measures assessed physical and psychosocial deficits, ability to perform activities of daily living, ability to function at school and/or work at the same level as before, ability to play every day, and the return to a subjectively normal life. Survey questions were developed based on GOSE-Peds interview questions and adapted to the Ugandan setting. Survey design and content experts were consulted prior to review by Ugandan collaborators to ensure that culturally appropriate and socioeconomically relevant questions were used. 


\section{Phone Follow-Up}

A Ugandan collaborator conducted the phone interviews using the participant's language. Participants provided verbal consent at the beginning of the phone call. The average duration of each interview was 20 minutes. A research coordinator reviewed each survey for data quality. If discrepancies were identified, participants were called again to clarify responses.

\section{Data Analysis}

Microsoft Excel 2013 was used for data collection and analysis. Descriptive statistics were calculated for demographics, mortality, follow-up healthcare, and quality of life measures. Chi-square tests were conducted to compare patient demographics between the surveyed $(n=142)$ and nonresponder $(\mathrm{n}=90)$ groups and between the phone number $(\mathrm{n}=232)$ and no phone number $(\mathrm{n}=85)$ groups. A $\mathrm{p}$ value less than 0.05 was considered significant. Neurological outcomes were assessed using the GOSE-Peds. Patients were categorized by severity of head trauma based on their admission GCS score: severe (GCS score $\leq 8$ ), moderate (GCS score 9-12), and mild (GCS score 13-15).

\section{Results}

\section{Inpatient Demographics}

Between 2014 and 2015, 347 pediatric head trauma patients were treated at MNRH, 113 (33\%) of whom were female (Table 1). The median age at presentation was 6 years, median time to presentation was 24 hours, and median length of stay was 5 days. Road traffic injury (249 [72\%]) was the most common mechanism of injury, followed by falls (32 [9\%]), assault (27 [8\%]), and being struck by an object (15 [4\%]). Almost half of the patients presented with mild TBI (161 [46\%]), 32\% (112) with moderate TBI, $17 \%$ (60) with severe TBI, and 4\% (14) had no mechanism of injury specified. Almost one-fifth of the patients (58 [17\%]) received surgical intervention. In-hospital mortality was $9 \%$ (30). At the end of their hospital stay, three-quarters of the patients (263 [76\%]) were discharged with a documented GCS score between 13 and 15, 11\% (39) with a score between 9 and 12, and none with a score below 9; discharge GCS scores were not specified for 15 patients (4\%). Phone numbers were documented for 232 discharged patients, and there was no statistically significant difference in the demographics and injury type and severity between the groups with and without phone numbers.

\section{Surveyed Patient and Caregiver Demographics}

A total of 142 patients were surveyed, 41 (29\%) of whom were female (Table 2). There was a statistically significant difference in the sex distribution between the surveyed and nonresponder groups (30 [33\%] of 90 were female, $p$ $=0.02$ ). No other statistically significant differences in the demographics were identified between the surveyed and nonresponder groups. Surgery was provided to $23(16 \%)$ of the surveyed patients: 3 craniotomies for epidural hematoma evacuation, 9 craniotomies for elevation of skull fracture, and 11 craniectomies for decompression of skull
TABLE 1. Summary of characteristics in 347 pediatric head trauma patients treated at MNRH between 2014 and 2015

\begin{tabular}{lc}
\hline \multicolumn{1}{c}{ Parameter } & Value \\
\hline Sex, no. (\%) & \\
Female & $113(33 \%)$ \\
Male & $234(67 \%)$ \\
\hline Median age at presentation in yrs (range) & $6(0.17-17)$ \\
\hline Median time to presentation in hrs & 24 \\
\hline Median length of stay in days & 5 \\
\hline Mechanism of injury, no. (\%) & \\
Road traffic injury & $249(72 \%)$ \\
Fall & $32(9 \%)$ \\
Assault & $27(8 \%)$ \\
Struck by object & $15(4 \%)$ \\
Not specified & $24(7 \%)$ \\
\hline TBl severity (admission GCS score), no. (\%) & \\
Severe ( $\leq 8)$ & $60(17 \%)$ \\
Moderate (9-12) & $112(32 \%)$ \\
Mild (13-15) & $161(46 \%)$ \\
Not specified & $14(4 \%)$ \\
\hline Received surgical intervention, no. (\%) & $58(17 \%)$ \\
\hline Discharged w/ phone no. on file, no. (\%) & $232(67 \%)$ \\
\hline Inpatient mortality & $30(9 \%)$ \\
\hline Discharge GCS score, no. (\%) & \\
$\leq 8$ (severe) & $0(0 \%)$ \\
9-12 (moderate) & $39(11 \%)$ \\
13-15 (mild) & $263(76 \%)$ \\
Not specified & $15(4 \%)$ \\
\hline
\end{tabular}

fracture. There was no statistically significant difference in the mortality rate or GOS-E scores between patients who received surgical intervention and those who did not. The median time to follow-up among the surveyed patients was 1.48 years. Most patients lived in the central region (92 [65\%]), where MNRH is located, followed by the western $(30[21 \%])$, eastern (13 [9\%]), and northern (7 [5\%]) regions. Almost three-quarters (105 [74\%]) of the caregivers were Christian, and 26\% (37) were Muslim. Close to half $(40.1 \%)$ of the caregivers had a primary education, and $85.2 \%$ had a secondary education or below. Most caregivers were farmers (47 [33\%]), businessmen (30 [21\%]), and skilled workers (24 [17\%]) such as construction workers, butchers, and mechanics.

\section{Mortality}

In the 1-year follow-up group of surveyed patients (n = 72), the mortality rate was 4\% (3). All 3 patients died within 30 days of discharge due to complications from the injury. In the 2-year follow-up group of surveyed patients $(\mathrm{n}=70)$, the mortality rate was $3 \%$ (2). One patient died following an assault 15 months postdischarge, and the other died of malaria 2 months postdischarge. The overall mortality rate, including inpatient deaths, was $10 \%(\mathrm{n}=35)$.

\section{Follow-Up Care}

Almost half $(48 \%)$ of the surveyed patients (1 year: 44\%, 2 years: $51 \%$ ) did not return to MNRH postdischarge. 
TABLE 2. Summary of characteristics in 142 surveyed patients and their caregivers

\begin{tabular}{|c|c|}
\hline Parameter & Value \\
\hline \multicolumn{2}{|l|}{ Sex, no. (\%) } \\
\hline Female & $41(29 \%)$ \\
\hline Male & $101(71 \%)$ \\
\hline Median age at presentation in yrs (range) & $6(0.17-17)$ \\
\hline Median time to FU in yrs & 1.48 \\
\hline \multicolumn{2}{|l|}{ Mechanism of injury, no. (\%) } \\
\hline Road traffic injury & $102(72 \%)$ \\
\hline Fall & $17(12 \%)$ \\
\hline Assault & $11(8 \%)$ \\
\hline Struck by object & $11(8 \%)$ \\
\hline Not specified & $1(1 \%)$ \\
\hline Received surgical intervention, no. (\%) & $23(16 \%)$ \\
\hline \multicolumn{2}{|l|}{ TBI severity (admission GCS score), no. (\%) } \\
\hline Severe $(\leq 8)$ & $21(15 \%)$ \\
\hline Moderate (9-12) & $44(31 \%)$ \\
\hline Mild (13-15) & $77(54 \%)$ \\
\hline \multicolumn{2}{|l|}{ Uganda region, no. (\%) } \\
\hline Central & $92(65 \%)$ \\
\hline Eastern & $13(9 \%)$ \\
\hline Northern & $7(5 \%)$ \\
\hline Western & $30(21 \%)$ \\
\hline \multicolumn{2}{|l|}{ Caregiver religion, no. (\%) } \\
\hline Muslim & $37(26 \%)$ \\
\hline Christian & $105(74 \%)$ \\
\hline \multicolumn{2}{|l|}{ Caregiver education, no. (\%) } \\
\hline None & $23(16.2 \%)$ \\
\hline Primary & $57(40.1 \%)$ \\
\hline Secondary & $41(28.9 \%)$ \\
\hline Diploma/certificate & $13(9.2 \%)$ \\
\hline Bachelor's degree & $7(4.9 \%)$ \\
\hline Unknown & $1(0.7 \%)$ \\
\hline \multicolumn{2}{|l|}{ Caregiver occupation, no. (\%) } \\
\hline Business & $30(21 \%)$ \\
\hline Farmer & $47(33 \%)$ \\
\hline Salaried worker & $14(10 \%)$ \\
\hline Skilled worker & $24(17 \%)$ \\
\hline Student & $1(1 \%)$ \\
\hline Other & $4(3 \%)$ \\
\hline Unemployed & $22(15 \%)$ \\
\hline
\end{tabular}

$\mathrm{FU}=$ follow-up.

One-third of the patients in the 1-year follow-up group and almost half of those (43\%) in the 2-year follow-up group did not receive any healthcare since their discharge from MNRH (Table 3). In the 1-year follow-up group, $47 \%$ of the patients were seen at a clinic and $17 \%$ were admitted to the hospital. In comparison, $41 \%$ of patients in the 2 -year follow-up group were seen at a clinic and $13 \%$ were admitted to the hospital. Follow-up for their initial injury accounted for $85 \%$ and $89 \%$ of any healthcare received since discharge by the 1-year and 2-year follow-up groups, respectively. Malaria was the second leading reason for care, at $9 \%$ and $8 \%$, respectively. Other reasons for receiving healthcare included mouth sores, stomach ache, cough, and vision problems.
TABLE 3. Healthcare received since discharge by the 1-year and 2-year follow-up groups

\begin{tabular}{lcr}
\hline \multicolumn{1}{c}{ Parameter } & 1-Yr FU Group & 2-Yr FU Group \\
\hline Healthcare since discharge, no. (\%) & & \\
Received healthcare & $46(64 \%)$ & $38(54 \%)$ \\
Hospital admission & $12(17 \%)$ & $9(13 \%)$ \\
Clinical visit & $34(47 \%)$ & $29(41 \%)$ \\
$\quad$ No healthcare & $23(32 \%)$ & $30(43 \%)$ \\
\hline Returned to MNRH for care, no. (\%) & $40(56 \%)$ & $34(49 \%)$ \\
\hline Reason for care, no. (\%) & & \\
Initial injury & $39(85 \%)$ & $34(89 \%)$ \\
Malaria & $4(9 \%)$ & $3(8 \%)$ \\
$\quad$ Other & $3(7 \%)$ & $1(3 \%)$ \\
\hline
\end{tabular}

\section{Neurological Outcomes: GOSE-Peds Scores}

The average GOSE-Peds scores for patients with severe (GCS score $\leq 8, \mathrm{n}=22$ ), moderate (GCS score 9-12, $\mathrm{n}=$ 28), and mild (GCS score 13-15, $\mathrm{n}=41$ ) trauma were 5.68 $\pm 2.85,4.79 \pm 2.38$, and $3.12 \pm 2.08$, respectively, for the 1-year follow-up group (Table 4) and $5.56 \pm 2.58(\mathrm{n}=16)$, $4.00 \pm 2.45(\mathrm{n}=26)$, and $2.21 \pm 1.49(\mathrm{n}=38)$, respectively, for the 2-year follow-up group (Table 5).

\section{Quality of Life Measures \\ General}

In the 1- and 2-year follow-up groups, $48 \%(\mathrm{n}=33)$ and $72 \%(\mathrm{n}=49)$, respectively, reported a return to a subjectively normal life (Table 6). Further, $84 \%(n=58)$ of those in the 1-year group and $96 \%(n=65)$ of those in the 2-year group reported a return to a subjectively normal or almost normal life. Moreover, 88\% ( $n=61)$ and $96 \%(n=65)$ of children played every day.

\section{Physical Deficits}

In the 1-year follow-up group, $28 \%(\mathrm{n}=19)$ reported physical movement problems, $22 \%(\mathrm{n}=15)$ had difficulty seeing, and $13 \%(\mathrm{n}=9)$ had difficulty hearing. In the 2-year follow-up group, $13 \%(\mathrm{n}=9), 15 \%(\mathrm{n}=10)$, and $9 \%$ $(n=6)$ reported physical movement problems, difficulty seeing, and difficulty hearing, respectively.

\section{Activities of Daily Living}

Approximately one-quarter of surveyed patients in each follow-up group required assistance with activities of daily living: bathing (1 year: 26\%, 2 years: $25 \%$ ), eating (28\% and $22 \%$ ), toileting (22\% and $22 \%$ ), dressing $(26 \%$ and $21 \%$ ), and hygiene (26\% and $19 \%)$.

\section{School and Work Function}

Three-quarters of the patients in each follow-up group were in school before their injury (1 year: 77\%, 2 years: $74 \%$ ), and $64 \%$ and $68 \%$, respectively, were in school after the injury. In the 1-year follow-up group, $17 \%$ were not in school because of their injury. In comparison, $7 \%$ of those in the 2-year follow-up group were not in school due to their injury. Of those in school, 64\% (1 year) and 70\% (2 years) were able to return to baseline function. 
TABLE 4. One-year follow-up GOSE-Peds scores by TBI severity, including inpatient deaths

\begin{tabular}{lcccc}
\hline \multicolumn{1}{c}{ GOSE-Peds Score } & GCS Score $\leq 8(n=22)$ & GCS Score 9-12 $(n=28)$ & GCS Score 13-15 $(n=41)$ & Total $(n=91)$ \\
\hline 8, death & 11 & 8 & 3 & 22 \\
\hline 7, vegetative state & 0 & 0 & 0 & 0 \\
\hline 6, lower severe disability & 4 & 3 & 3 & 0 \\
\hline 5, upper severe disability & 0 & 0 & 12 & 20 \\
\hline 4, lower moderate disability & 1 & 7 & 6 & 12 \\
\hline 3, upper moderate disability & 1 & 5 & 3 & 14 \\
\hline 2, lower good recovery & 1 & 4 & $3.12 \pm 2.08$ & $4.25 \pm 2.58$ \\
\hline 1, upper good recovery & 4 & 1 & $4.79 \pm 2.38$ & 19 \\
\hline Average score & $5.68 \pm 2.85$ & 4.79 & & 0 \\
\hline
\end{tabular}

$\mathrm{n}=$ number of patients.

Regarding the ability to work, 65\% (1 year) and 38\% (2 years) of patients had worked prior to their injury, and $58 \%$ and $47 \%$, respectively, worked after their injury. In the 1-year and 2-year follow-up groups, $17 \%$ and $7 \%$ of patients, respectively, were unable to work because of their injury. Of those working, $71 \%$ (1 year) and 69\% (2 years) were able to return to baseline function.

\section{Psychosocial Function}

Almost all participants in both groups were reportedly friendly (1 year: 91\%, 2 years: 99\%), responsible (91\% and 97\%), displaying emotions (97\% and 99\%), and behaving well with parents (94\% and 97\%) as compared to others their age.

\section{Discussion}

\section{Summary}

In this study, we surveyed pediatric head trauma patients from all regions of Uganda, with most residing in the central region where the MNRH is located. Most caregivers had some primary or secondary education, and the most common occupations among them were farming and business. The leading cause of TBI in this patient population was road traffic injury (RTI), followed by falls, assault, and being struck by an object. Surgical intervention was provided for 23 patients (16\%). Approximately half of the patients did not return to MNRH postdischarge, with more than one-third not receiving any subsequent healthcare. Follow-up for their initial injury was the primary reason for receiving healthcare. The neurosurgical outcomes of pediatric trauma patients seen at MNRH are promising, with low mortality and $72 \%$ of patients reporting a return to a subjectively normal life by 2 years postdischarge. Our results showed severe disability, lower moderate disability, and upper good recovery in patients with severe, moderate, and mild head trauma, respectively, by 2 years. In our study, $61 \%$ of mild TBI patients, $27 \%$ of moderate TBI patients, and $13 \%$ of severe TBI patients showed good recovery by 2 years. In comparison, $98 \%, 77 \%$, and $58 \%$ of mild, moderate, and severe TBI patients, respectively, in a comparable US study showed good recovery by 2.5 years. ${ }^{1}$

\section{Phone Follow-Up}

We had a $61 \%$ response rate from patients from all regions of Uganda. Other pediatric neurosurgical follow-up studies in Uganda have been conducted in the eastern region via home visits. In these studies, Warf et al. were able to follow up pediatric myelomeningocele, encephalocele, and brain tumor patients with response rates ranging from $67 \%$ to $98 \%$. $^{24,25,30,31}$ While our pilot study was unable to obtain follow-up rates that were as high, we still feel ours is a viable method to continue to explore. With just five attempts at phone calls, we obtained a relatively high re-

TABLE 5. Two-year follow-up GOSE-Peds scores by TBI severity, including inpatient deaths

\begin{tabular}{lcccc}
\hline \multicolumn{1}{c}{ GOSE-Peds Score } & GCS Score $\leq 8(n=16)$ & GCS Score 9-12 $(n=26)$ & GCS Score 13-15 $(n=38)$ & Total $(n=80)$ \\
\hline 8, death & 7 & 5 & 0 & $12^{*}$ \\
\hline 7, vegetative state & 0 & 0 & 0 & 0 \\
\hline 6, lower severe disability & 2 & 2 & 1 & 5 \\
\hline 5, upper severe disability & 0 & 0 & 11 & 0 \\
\hline 4, lower moderate disability & 4 & 8 & 3 & 23 \\
\hline 3, upper moderate disability & 1 & 4 & 2 & 3 \\
\hline 2, lower good recovery & 0 & 1 & 21 & 29 \\
\hline 1, upper good recovery & 2 & 6 & $2.21 \pm 1.49$ & $2.81 \pm 1.84$ \\
\hline Average score & $5.56 \pm 2.58$ & $4.00 \pm 2.45$ & & 0 \\
\hline
\end{tabular}

* An admission GCS score was not documented for a patient who died while an inpatient; therefore, this patient was excluded from this analysis. 
TABLE 6. Quality of life measures in 137 surveyed patients

\begin{tabular}{|c|c|c|}
\hline Measure & $\begin{array}{l}1-Y r \text { FU } \\
(n=69)\end{array}$ & $\begin{array}{l}2-Y r F U \\
(n=68)\end{array}$ \\
\hline \multicolumn{3}{|l|}{ General } \\
\hline Normal & $48 \%$ & $72 \%$ \\
\hline Normal or almost normal & $84 \%$ & $96 \%$ \\
\hline Plays every day & $88 \%$ & $96 \%$ \\
\hline \multicolumn{3}{|l|}{ Neurological function } \\
\hline Physical movement problem & $28 \%$ & $13 \%$ \\
\hline Difficulty w/ vision & $22 \%$ & $15 \%$ \\
\hline Difficulty w/ hearing & $13 \%$ & $9 \%$ \\
\hline Assistance w/ bathing & $26 \%$ & $25 \%$ \\
\hline Assistance w/ eating & $28 \%$ & $22 \%$ \\
\hline Assistance w/ toileting & $22 \%$ & $22 \%$ \\
\hline Assistance w/ dressing & $26 \%$ & $21 \%$ \\
\hline Assistance w/ hygiene & $26 \%$ & $19 \%$ \\
\hline Can follow commands & $88 \%$ & $100 \%$ \\
\hline Can say words & $100 \%$ & $100 \%$ \\
\hline Can follow complex commands & $88 \%$ & $88 \%$ \\
\hline Can follow instructions from 5 mins ago & $77 \%$ & $90 \%$ \\
\hline Can do chores & $77 \%$ & $87 \%$ \\
\hline \multicolumn{3}{|l|}{ School \& work } \\
\hline In school before injury & $77 \%$ & $74 \%$ \\
\hline In school after injury & $64 \%$ & $68 \%$ \\
\hline Normal function at school & $64 \%$ & $70 \%$ \\
\hline Not in school due to injury & $17 \%$ & $7 \%$ \\
\hline Work before injury & $65 \%$ & $38 \%$ \\
\hline Work after injury & $58 \%$ & $47 \%$ \\
\hline Normal function at work & $71 \%$ & $69 \%$ \\
\hline Not working due to injury & $17 \%$ & $7 \%$ \\
\hline \multicolumn{3}{|l|}{ Psychosocial function } \\
\hline Friendly & $91 \%$ & $99 \%$ \\
\hline Responsible & $91 \%$ & $97 \%$ \\
\hline Displays emotion & $97 \%$ & $99 \%$ \\
\hline Behaves w/ parents & $94 \%$ & $97 \%$ \\
\hline
\end{tabular}

sponse rate of $61 \%$, which perhaps could be higher if we increased the number of attempts at phone calls. Furthermore, we were able to reach a much larger population distributed throughout the entire country instead of just the area immediately adjacent to the hospital. Our method is also much less time intensive and costly than hiring staff for home visits. With continued refinement in our method and even further penetration of cell phone access throughout Uganda, we feel our method will yield even higher response rates.

Our phone follow-up highlighted the challenges in follow-up care faced at MNRH. Although 59\% of patients received follow-up care, only $52 \%$ returned to MNRH for their care. In a setting in which patient records are kept on paper, there is no centralized medical record system to transfer patient data among hospitals and clinics. Moreover, $37 \%$ of patients received no healthcare postdischarge. Thus, phone follow-up provided a means of reaching pa- tients who would otherwise have been lost to follow-up. Future studies can utilize phone calls as interventions to improve follow-up care.

\section{Normalcy After Pediatric Head Trauma}

By the 2-year follow-up, $72 \%$ of participants reported a return to a subjectively normal life, and $96 \%$ reported a return to a subjectively normal or almost normal life. Although one-quarter of surveyed patients reported physical deficits or required assistance with activities of daily living, $96 \%$ of them played daily and the majority were able to return to school or work. Only $7 \%$ were unable to return to school or work because of their injury at the 2-year follow-up. Of those who did return to school or work, $70 \%$ were able to function at their baseline by the 2-year followup. These findings highlight the differences between what clinicians and patients may perceive as "normal or almost normal life." It is reassuring that despite a significant number of patients having reported physical deficits, the majority are able to study, work, and play-thus returning to normalcy.

\section{Mortality and Neurological Outcomes Compared to Those in the US}

Overall mortality for our pediatric head trauma patients was $10 \%$, and TBI-related mortality was $9.8 \%$, which is substantially higher than that reported in the US. The Centers for Disease Control and Prevention reports TBI-related mortality in the US as 24 cases per 100,000 persons in the $1-4$ age group, 12.7 cases per 100,000 persons in the 5-14 age group, and 45.5 cases per 100,000 persons in the $15-$ 19 age group (https://www.cdc.gov/traumaticbraininjury/ data/rates_deaths_byage.html).

One factor affecting the observed mortality differences is mechanism of injury. In our study, RTIs were the leading cause of pediatric TBI hospitalizations and deaths. The majority $(94 \%)$ of these patients were pedestrians hit by a car or motorcycle. In comparison, falls are the leading cause of pediatric TBI hospitalizations in the US, followed by blunt trauma and RTIs (https://www.cdc.gov/ TraumaticBrainInjury/data/index.html). However, RTIs are the leading cause of pediatric TBI-related deaths in the US. ${ }^{5}$ Therefore, the increased mortality in our study may in part be attributable to the increased proportion of RTIs. Further research is warranted to identify determinants of mortality in this population. Moreover, the high proportion of pediatric pedestrian RTIs emphasizes the need for improved road safety.

In our study, severe and moderate TBI patients had GOSE-Peds scores associated with severe disability and moderate disability, respectively, by the 2-year followup. Mild TBI patients reported moderate disability at the 1-year follow-up and good recovery at the 2-year followup. A comparable study in the US showed moderate disability in severe TBI patients and good recovery for those with moderate and mild TBI at the 30-month follow-up. ${ }^{1}$ These findings suggest greater disability in Ugandan patients with moderate TBI as compared to their US counterparts. This finding could be related to a lack of supportive medical resources such as rehabilitation, medication, and medical care for concomitant injuries. Future studies 
should explore whether targeted interventions such as increased access to physical therapy might change the outcome in these patients.

\section{Study Limitations}

The low availability of in-patient data limited further analysis in this study. The database from which we identified eligible patients reported the surgical interventions performed but did not otherwise document treatment and hospital course. There was no statistically significant difference in mortality or GOSE-Peds scores between those who received surgical intervention and those who did not. Since almost one-fifth (17\%) of the inpatients underwent surgery, it is unclear how many of the remaining patients in the cohort did not require surgery and how many required surgery but did not receive it. In prior studies from MNRH, those awaiting surgery but who did not undergo surgery had the greatest risk for death. ${ }^{13,29}$ Future studies should explore the impact of hospital interventions on long-term mortality and neurological outcomes.

A limitation of this study as compared to studies utilizing home visits is the reliability of caregiver responses. Although the majority of caregivers had some primary or secondary education, medical information specifically related to causes of death or complications since discharge was difficult to obtain. However, the caregiver was able to provide extensive responses on the child's quality of life and follow-up healthcare.

This study was biased toward those patients willing and able to respond to a phone survey. The only statistically significant difference between the surveyed and nonresponder groups was the sex distribution, with fewer females in the surveyed group. There was no statistically significant difference between patients with documented phone numbers and those without. Nevertheless, phone surveys may bias against patients of a lower socioeconomic status since they may not have access to a phone. An encouraging finding, however, was our ability to reach patients throughout all regions of Uganda. Half of the caregivers had no or only a primary education, and a third were farmers. These demographics suggest that a substantial portion of patients with a low socioeconomic status owned a phone and were willing to complete a follow-up survey through this method. Future studies could increase response rates by improving documentation of follow-up phone numbers, emphasizing the importance of follow-up interviews, and increasing the number of call attempts.

\section{Conclusions}

To our knowledge, this is the first study reporting longterm pediatric head trauma patient outcomes in Uganda. Our results demonstrated low mortality, good recovery in mild TBI patients, but poor long-term recovery in patients with moderate and severe TBI at the 2-year follow-up. This study additionally confirmed the feasibility of phone follow-up for pediatric head trauma patients throughout all regions of Uganda who are treated at the national referral hospital. Prior Ugandan studies have utilized home visits for follow-ups, ${ }^{30,31}$ but the cost and time-consuming nature of such visits restrict their use to a few surrounding dis- tricts and are therefore not a viable option for a national referral hospital. This study provides a starting point for further phone follow-up with patient populations in both neurosurgery and other subspecialties in this setting.

\section{Acknowledgments}

We would like to acknowledge the funding provided by the Stanford Medical Scholars Fellowship Program.

\section{References}

1. Anderson VA, Catroppa C, Haritou F, Morse S, Rosenfeld JV: Identifying factors contributing to child and family outcome 30 months after traumatic brain injury in children. $\mathbf{J}$ Neurol Neurosurg Psychiatry 76:401-408, 2005

2. Barr ML, Ferguson RA, Steel DG: Inclusion of mobile telephone numbers into an ongoing population health survey in New South Wales, Australia, using an overlapping dualframe design: impact on the time series. BMC Res Notes 7:517, 2014

3. Beers SR, Wisniewski SR, Garcia-Filion P, Tian Y, Hahner $\mathrm{T}$, Berger RP, et al: Validity of a pediatric version of the Glasgow Outcome Scale-Extended. J Neurotrauma 29:1126-1139, 2012

4. Centers for Disease Control and Prevention: Traumatic Brain Injury in the United States: Epidemiology and Rehabilitation. Atlanta: Centers for Disease Control and Prevention, 2018 (https://www.cdc.gov/traumaticbraininjury/ pubs/congress_epi_rehab.html) [Accessed August 20, 2018]

5. Chevignard M, Francillette L, Toure H, Brugel D, Meyer $\mathrm{P}$, Vannier AL, et al: Academic outcome, participation and health-related quality of life following childhood severe traumatic brain injury: results of a prospective longitudinal study: the seven-year follow-up of the TGE cohort. Ann Phys Rehabil Med 59:e133, 2016

6. Dal Grande E, Chittleborough CR, Campostrini S, Taylor AW: Bias of health estimates obtained from chronic disease and risk factor surveillance systems using telephone population surveys in Australia: results from a representative faceto-face survey in Australia from 2010 to 2013. BMC Med Res Methodol 16:44, 2016

7. Dewan MC, Mummareddy N, Wellons JC III, Bonfield CM: Epidemiology of global pediatric traumatic brain injury: qualitative review. World Neurosurg 91:497-509, 509.e1, 2016

8. Emanuelson I, Wendt LV: Epidemiology of traumatic brain injury in children and adolescents in south-western Sweden. Acta Paediatr 86:730-735, 1997

9. Fulkerson DH, White IK, Rees JM, Baumanis MM, Smith JL, Ackerman LL, et al: Analysis of long-term (median 10.5 years) outcomes in children presenting with traumatic brain injury and an initial Glasgow Coma Scale score of 3 or 4 . J Neurosurg Pediatr 16:410-419, 2015

10. Haglund MM, Kiryabwire J, Parker S, Zomorodi A, MacLeod D, Schroeder R, et al: Surgical capacity building in Uganda through twinning, technology, and training camps. World J Surg 35:1175-1182, 2011

11. Jennett B, Bond M: Assessment of outcome after severe brain damage. Lancet 1:480-484, 1975

12. Keenan HT, Bratton SL: Epidemiology and outcomes of pediatric traumatic brain injury. Dev Neurosci 28:256-263, 2006

13. Kuo BJ, Vaca SD, Vissoci JRN, Staton CA, Xu L, Muhumuza $\mathrm{M}$, et al: A prospective neurosurgical registry evaluating the clinical care of traumatic brain injury patients presenting to Mulago National Referral Hospital in Uganda. PLoS One 12:e0182285, 2017

14. Larmarange J, Kassoum O, Kakou E, Fradier Y, Sika L, 
Danel C: Faisabilité et représentativité d'une enquête téléphonique avec échantillonnage aléatoire de lignes mobiles en Côte d'Ivoire. Population (Paris) 71:121, 2016

15. Larson-Dupuis C, De Beaumont L: The need for a long-term multidisciplinary follow-up in the management of mTBI. Expert Rev Neurother 16:1-3, 2016

16. Li C, Balluz LS, Okoro CA, Strine TW, Lin JM, Town M, et al: Surveillance of certain health behaviors and conditions among states and selected local areas-Behavioral Risk Factor Surveillance System, United States, 2009. MMWR Surveill Summ 60:1-250, 2011

17. McAllister S, Ganefianty A, Faried A, Sutiono AB, Sarjono $\mathrm{K}$, Melia R, et al: The Bandung neurosurgery patient outcomes project, Indonesia (Part I): methods, participant characteristics, and pre-discharge outcomes. Int J Health Plann Manage 33:e57-e66, 2018

18. McCauley SR, Wilde EA, Anderson VA, Bedell G, Beers SR, Campbell TF, et al: Recommendations for the use of common outcome measures in pediatric traumatic brain injury research. J Neurotrauma 29:678-705, 2012

19. Mitra B, Cameron PA, Butt W, Rosenfeld JV: Children or young adults? A population-based study on adolescent head injury. ANZ J Surg 76:343-350, 2006

20. Okoro CA, Zhao G, Fox JB, Eke PI, Greenlund KJ, Town M: Surveillance for health care access and health services use, adults aged 18-64 years-Behavioral Risk Factor Surveillance System, United States, 2014. MMWR Surveill Summ 66:1-42, 2017

21. Pew Research Center: Cell phones in Africa: communication lifeline. Pew Research Center Global Attitudes \& Trends. April 15, 2015 (http://www.pewglobal.org/2015/04/15/cellphones-in-africa-communication-lifeline/) [Accessed August 20, 2018]

22. Ryan NP, van Bijnen L, Catroppa C, Beauchamp MH, Crossley L, Hearps S, et al: Longitudinal outcome and recovery of social problems after pediatric traumatic brain injury (TBI): Contribution of brain insult and family environment. Int $\mathbf{J}$ Dev Neurosci 49:23-30, 2016

23. Schrieff LE, Thomas KG, Dollman AK, Rohlwink UK, Figaji AA: Demographic profile of severe traumatic brain injury admissions to Red Cross War Memorial Children's Hospital, 2006-2011. S Afr Med J 103:616-620, 2013

24. Sims-Williams HJ, Sims-Williams HP, Kabachelor EM, Fotheringham J, Warf BC: Ten-year survival of Ugandan infants after myelomeningocele closure. J Neurosurg Pediatr 19:70-76, 2017

25. Stagno V, Mugamba J, Ssenyonga P, Kaaya BN, Warf BC: Presentation, pathology, and treatment outcome of brain tumors in 172 consecutive children at CURE Children's Hospital of Uganda. The predominance of the visible diagnosis and the uncertainties of epidemiology in sub-Saharan Africa. Childs Nerv Syst 30:137-146, 2014
26. Sutiono AB, Faried A, McAllister S, Ganefianty A, Sarjono $\mathrm{K}$, Arifin MZ, et al: The Bandung neurosurgery patient outcomes project, Indonesia (Part II): Patient pathways and feasibility and acceptability of telephone follow-up. Int J Health Plann Manage 33:e49-e56, 2018

27. Teasdale GM, Pettigrew LE, Wilson JT, Murray G, Jennett $\mathrm{B}$ : Analyzing outcome of treatment of severe head injury: a review and update on advancing the use of the Glasgow Outcome Scale. J Neurotrauma 15:587-597, 1998

28. Udoh DO, Adeyemo AA: Traumatic brain injuries in children: a hospital-based study in Nigeria. Afr J Paediatr Surg 10:154-159, 2013

29. Vaca SD, Kuo BJ, Nickenig Vissoci JR, Staton CA, Xu LW, Muhumuza M, et al: Temporal delays along the neurosurgical care continuum for traumatic brain injury patients at a tertiary care hospital in Kampala, Uganda. Neurosurgery [epub ahead of print], 2018

30. Warf BC, Tracy S, Mugamba J: Long-term outcome for endoscopic third ventriculostomy alone or in combination with choroid plexus cauterization for congenital aqueductal stenosis in African infants. J Neurosurg Pediatr 10:108-111, 2012

31. Warf BC, Wright EJ, Kulkarni AV: Factors affecting survival of infants with myelomeningocele in southeastern Uganda. J Neurosurg Pediatr 7:127-133, 2011

32. Zhang J, Joshi R, Sun J, Rosenthal SR, Tong M, Li C, et al: A feasibility study on using smartphones to conduct shortversion verbal autopsies in rural China. Popul Health Metr 14:31, 2016

\section{Disclosures}

The authors report no conflict of interest concerning the materials or methods used in this study or the findings specified in this paper.

\section{Author Contributions}

Conception and design: all authors. Acquisition of data: Vaca, Nalwanga, C Muhumuza, Lerman. Analysis and interpretation of data: Grant, Vaca, Xu, Nalwanga, C Muhumuza, Kiryabwire, Ssenyonjo, Mukasa, M Muhumuza, Haglund. Drafting the article: Grant, Vaca, Xu. Critically revising the article: all authors. Reviewed submitted version of manuscript: all authors. Approved the final version of the manuscript on behalf of all authors: Grant. Study supervision: Grant, Xu, Kiryabwire, Ssenyonjo, Mukasa, M Muhumuza, Haglund.

\section{Correspondence}

Gerald Grant: Stanford University, Stanford, CA. ggrant2@ stanford.edu. 